\title{
História das reformas administrativas no Brasil: narrativas, teorizações e representações*
}

Frederico Lustosa da Costa

\section{Introdução}

Quase tão discutida quanto as próprias reformas administrativas contemporâneas, a história das experiências de mudança institucional planejada do Estado brasileiro tem merecido a atenção de muitos estudiosos da matéria, chegando quase a constituir um objeto à parte. De fato, a maioria dos trabalhos sobre as reformas mais recentes se encarrega de recuperar os principais antecedentes desses processos de transformação. Assim, existem hoje inúmeros relatos, análises e estudos sobre as experiências de reforma da administração pública federal brasileira, com diferentes abordagens, graus de profundidade e níveis de implicação com os projetos. Muitos estudiosos são eles mesmos reformadores, tendo atuado como ideólogos, mentores, gestores ou agentes das reformas que se realizaram no Brasil desde a década de 30. Nesse sentido, a literatura é diretamente implicada, sem que os eventuais envolvimentos (ou estranhamentos) dos autores sejam explicitados. Relatos, narrativas, teorizações, interpretações e ideologias se confundem. Em qualquer um dos 
casos, constituem representações do mundo administrativo brasileiro, quer dizer, apresentam-se como formas simbólicas de um Estado em transformação.

Este trabalho se propõe a oferecer uma modesta contribuição ao estudo da história das reformas administrativas realizadas no Brasil a partir da primeira metade do século $\mathrm{XX}$. Mais do que apresentar uma cronologia de fatos e um repertório de projetos, recupera as narrativas e análises dos estudiosos do tema para identificar as diferentes explicações para os sucessos e insucessos do passado e estabelecer um sistema de categorias que seja útil à compreensão da dinâmica histórica. Esse esforço de reconstituição deve levar em conta as seguintes questões-guia:

- Qual ou quais os diagnósticos que ensejaram as reformas?

- Qual o veredicto em termos de sucesso ou fracasso de cada experiência?

- Em que consistem o sucesso e o fracasso?

- Por que fracassaram? Ou por que foram exitosas?

O trabalho apresenta as diferentes narrativas na seqüência das reformas analisadas, tentando seguir a ordem cronológica dos artigos estudados. Assim, o texto começa com a discussão da reforma burocrática da Era Vargas e termina com as apreciações sobre a reforma gerencial do governo FHC. Entretanto, a qualquer momento, por iniciativas dos próprios narradores, as comparações são evocadas e as reformas anteriores são retomadas.

\section{Por que as reformas administrativas falham?}

A maioria das análises históricas sobre as reformas administrativas brasileiras se propõe a oferecer determinações para o relativo fracasso dessas tentativas. Tais explicações partem de razões de natureza geral, baseadas em relatos e reflexões sobre as experiências de outros países.

$\mathrm{Na}$ literatura internacional é apontado um amplo leque de causas para o insucesso de processos de reforma. Grande número de autores concorda que as reformas administrativas dificilmente atingem os resultados pretendidos. Caiden (1999) analisou um grande número de reformas realizadas ao redor do mundo e concluiu que a maioria delas, não obstante os esforços governamentais e o apoio de organismos internacionais, produziu resultado muito aquém do esperado, revelando uma tendência comum à descontinuidade.

Os governos prometem muito, mas freqüentemente falham em aumentar sua performance porque suas reformas se mostram desapontadoras. As reformas falham em produzir impacto significativo; elas seguem na direção errada ou são ultrapassadas pelos acontecimentos. Os reformistas têm sido otimistas e, muitas vezes, irrealistas; eles freqüentemente caem na armadilha da implementação. As reformas precisam de amplo apoio político e direção competente. Os reformistas precisam ter paciência e aceitar o que realmente podem alcançar, ainda que esses resultados estejam abaixo de suas intenções (p. 823) ${ }^{1}$.

Flávio Rezende (2004) repertoria parte da bibliografia existente para explicar o que ele chama de falha seqüencial, ou seja, a descontinuidade, o abandono e o término de processos de intervenção, sem que seus objetivos sejam alcançados ou que tenha havido melhoria de performance no aparato burocrático. Entre as principais 
causas apontadas estão: a sólida institucionalização dos elementos a serem reformados; a resistência organizada de setores afetados; o surgimento de conseqüências inesperadas; a existência de objetivos, interesses e valores diversificados ou conflitantes; a falta de foco na mudança por parte dos atores estratégicos; as incertezas, ambigüidades e complexidades inerentes à mudança; o deslocamento de objetivos; os movimentos contraditórios de descentralização e coordenação e a criação de expectativas exageradas (p. 33-45). A maior parte dessas razões diz respeito a mecanismos de resistência à mudança, identificados desde Maquiavel (2006), que reconhecia serem incertos os resultados de qualquer tentativa de introdução de uma nova ordem, pois "aquele que a introduz terá por inimigos todos os que da velha ordem extraíam privilégios e por tímidos defensores todos os que das vantagens da nova ordem poderiam usufruir" (p. 26).

\section{Narrativas e interpretações}

Na bibliografia brasileira, Beatriz Wahrlich, antiga colaboradora de Luís Simões Lopes ${ }^{2}$ no DASP e na Fundação Getúlio Vargas, que participou ativamente da reforma dos anos trinta, escreveu alguns dos primeiros artigos que compõem essa série de narrativas. Seus trabalhos são bastante descritivos, o que é uma vantagem, pois são ricos de informação e documentação. Suas análises cobrem um vasto conjunto de iniciativas que começam na instalação do governo provisório, em 3 de novembro de 1930, e terminam com o Programa Nacional de Desburocratização, instituído em 18 de julho de 1979, passando, evidentemente, pela reforma de 1967 . O trabalho de maior fôlego, entretanto, foi a análise da reforma administrativa na Era Vargas (WAhrlich, 1983). Sua apreciação sobre essa experiência ficou consagrada.

A característica reformista mais marcante desse período foi a ênfase na reforma dos meios (atividades de administração geral) mais do que nas dos próprios fins (atividades substantivas). Também digna de nota é a declarada observância, pelos líderes reformistas, da teoria

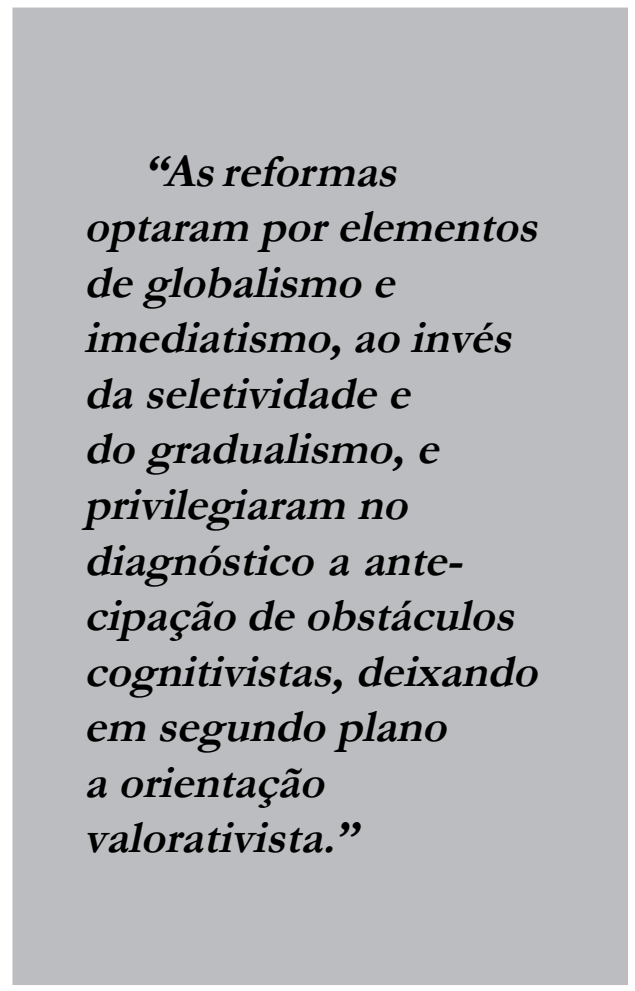

administrativa que consagrava a existência de "princípios de administração".

Tratava-se, assim, de uma reforma que adotava como modelo o prescrito na teoria administrativa então em voga nos países mais desenvolvidos. Era, em suma, uma "reforma modernizadora", inspirada nas melhores fontes disponíveis à época, ou seja, num modelo taylorista/fayoliano/ weberiano (WAHRLICH, 1974, p. 28). 
Embora precedendo em alguns poucos anos a publicação dos artigos de Beatriz Wahrlich, o trabalho de Kleber Nascimento adota uma abordagem analítica que o coloca como pioneiro de uma tradição bastante posterior. Em 1967, logo após a edição do Decreto-lei no 200, Nascimento (1967) publicou, no primeiro número da RAP, um artigo em que examinava as estratégias de reforma administrativa no Governo Federal. Pretendia analisar a experiência brasileira, tomando como ponto de referência três componentes fundamentais do modelo de estratégia - ação, conteúdo e valor. A ênfase das análises acabava recaindo no projeto "daspiano", embora também se valesse dos dados das iniciativas que se seguiram ao projeto do Estado Novo. Segundo sua percepção, o modelo estratégico das reformas administrativas brasileiras pode ser configurado como a seguir:

Componente operativo: ação

- Foco de ação: elementos formais

- Estilo de influenciação: impositivo

- Dinâmica de poder: insulativa Componente substantivo: conteúdo

- Escopo de mudança: globalistaimediatista

- Orientação diagnóstica: cognitivismo Componente ideológico: valor

- Estratégia e pré-requisitos comportamentais

- Estratégia e orientação processualista (Nascimento, 1967, p. 19).

Embora marcado pelo viés comportamentalista em voga na teoria administrativa, ainda que nuançado, o estudo de Kleber Nascimento reconhece os méritos da racionalização e as conquistas das reformas de 1937 e 1967, mas aponta aquelas distorções que comprometem a efetividade dos impactos e sua sustentabilidade a longo prazo. A ênfase nos aspectos formais dos sistemas administrativos, quer dizer, os arranjos estruturais da burocracia, o caráter impositivo das medidas reformistas, em detrimento da flexibilidade e da internalização das propostas e a dinâmica insulativa, que isolava os agentes de mudança das lideranças dos sistemas que deveriam ser objeto de intervenção, constituem o componente operativo. No que diz respeito ao componente substantivo, as reformas optaram por elementos de globalismo e imediatismo, ao invés da seletividade e do gradualismo, e privilegiaram no diagnóstico a antecipação de obstáculos cognitivistas, deixando em segundo plano a orientação valorativista. Finalmente, o componente ideológico ou conceitual que condiciona os demais aliava pré-requisitos comportamentais a uma orientação processualista.

Examinando com distanciamento histórico essas observações de Nascimento, é possível dizer que a maior parte dos elementos das estratégias das reformas era ditada pelo estado da arte do conhecimento em administração pública e pelas condições políticas em que elas foram intentadas ou implementadas. A reforma dos anos trinta, realizada em plena ditadura, revela-se formalista, ambiciosa e autoritária. As tentativas seguintes, ocorridas na década de cinqüenta, que se guiavam pelas mesmas dimensões estratégicas, provavelmente não lograram implementar-se justamente por lhes faltar a força do regime autoritário.

Esse tipo de análise aplicado à reforma administrativa de 1967 identificaria nos três componentes os mesmos elementos, embora alguns deles tenham deslocado-se em direção aos contrapontos indicados por Nascimento. Assim, a reforma incorporou certa dose de gradualismo e seletivismo na sua implementação e criou 
condições para uma maior interação entre agentes de mudanças e lideranças organizacionais (WAHRLICH, 1974, p. 71).

Gileno Fernandes Marcelino foi protagonista da tentativa de reforma administrativa no governo de transição para a democracia, a chamada Nova República. Ao descrever e analisar essa experiência, ele também realiza uma recuperação histórica das reformas precedentes, distinguindo três períodos, a saber: "a partir de 1930 até meados de 1945, com extensão de 1952 até meados de 1962, quando se realizam estudos não-implantados; a partir de 1964; e após 1985" (MarCelino, 1988, p. 37). Na descrição do primeiro período, repete a apreciação corrente sobre a ênfase na reforma dos meios e a orientação autocrática e impositiva.

O segundo período marca a substituição do "modelo clássico" pelo chamado modelo de "administração para o desenvolvimento", " voltado fundamentalmente para a expansão da intervenção do Estado na vida econômica e social e para a descentralização das atividades do setor público, tendo como premissas básicas a substituição de funcionários estatutários por celetistas (...) e a criação de entidades de administração indireta para a realização da intervenção econômica do Estado" (Ibid, p. 41). $\mathrm{O}$ autor considera que o Decreto-lei $\mathrm{n}^{\circ}$ 200 "representou, sem dúvida, um segundo momento importante dentro das tentativas de reforma administrativa promovidas pela administração pública brasileira ao estabelecer uma nova abertura conceitual, permitindo acelerar um processo de adaptação da máquina administrativa para torná-la mais eficaz". Destaca como aspectos inovadores o tríplice sentido da descentralização "dentro dos quadros da administração federal; da administração governamental para a órbita privada; e da União para os governos locais" e o "estabelecimento do conceito de sistemas administrativos para as funções comuns a todos os órgãos, o que em princípio facilitou a descentralização da gestão de recursos (pessoal, material, finanças)" (Ibid, p. 43-44). Segundo seu ponto de vista, "ao contrário das tentativas anteriores de reforma administrativa marcadas por um sentido de condução do processo e pelas tentativas de soluções globais, o Decreto-lei no 200 constituiuse mais em um plano indicativo ou carta de intenções, estabelecendo conceitos e princípios, do que em uma norma determinística" (Idem). Essa opinião é no mínimo controversa. Apesar da incorporação de certas características de gradualismo, seletividade e cooptação reconhecidos por Wahrlich, conforme indicado logo acima, a escolha do tipo de instrumento legal característico do regime autoritário - o decreto-lei, o sentido uniformizador de seus aspectos organizativos e o estabelecimento de normas estritas com relação à aquisição e contratos e ao controle estão longe de caracterizar um plano meramente indicativo.

Cabe ainda mencionar na análise de Marcelino o diagnóstico da administração federal no alvorecer da Nova República, que apontava como disfunções gerais a ineficácia do planejamento governamental; deficiências de mecanismos de implementação, coordenação e avaliação de ações de reforma/modernização dos órgãos; dissociação entre planejamento, modernização e recursos humanos; atuação pouco integrada e coordenada de órgãos ligados à área; e pouca prioridade à área de recursos humanos. Essas distorções traziam como conseqüências o escapismo da multiplicação de órgãos 
e entidades; marginalização do funcionalismo e descontinuidade administrativa; enfraquecimento da imagem do DASP; e perda de poder e status.

Passados alguns anos dessa tentativa de reforma, Marcelino (2003) atribui seu fracasso a problemas políticos decorrentes da natureza do governo de transição, da coalizão de facções heterogêneas que o apoiavam e da falta de liderança institucionalizada. Ainda assim, acredita que, além de deixar uma primeira versão da LeiOrgânica da Administração Pública Federal, a atuação da Secretaria de Administração Pública (SEDAP), então criada e por ele dirigida, "teve relativo sucesso em iniciativas de reforma como a implantação da ENAP e alguns instrumentos na área de serviços gerais" (MARCELINO, 2003, p. 648).

Além de trabalhos de perspectiva histórica, há estudos que privilegiam a indicação de características ou disfunções da administração pública brasileira. Tal é o caso do artigo de Belmiro Valverde Castor e Célio França (1986):

Como legado dos anos setenta, eles identificavam, entre muitas outras disfunções, a fragmentação do aparato administrativo central através da multiplicação de agências governamentais, da impossibilidade real do exercício de supervisão ministerial, dificultando e mesmo impedindo o cumprimento de funções essenciais de coordenação governamental em todos os setores, a falência da já precária política de pessoal, por força da proliferação de regimes jurídicos e salários diferenciados (p. 4).

Nos anos oitenta, não obstante a crise econômica e as rápidas transformações sociais, políticas e institucionais, a adminis- tração pública reagia lenta e insatisfatoriamente, pois estava condicionada por características do modelo brasileiro de desenvolvimento e administração. Esse modelo tinha como pressupostos uma concepção do Governo como Deusex-machina do processo de mudança social e um conceito convencional de desenvolvimento. A crença na centralidade do papel do Governo, "conduzindo, orientando, disciplinando e impregnando com seus valores o processo de mudança social", acabou impregnando a administração pública brasileira de quatro fascínios que estão na raiz das disfuncionalidades das estruturas e da operação do aparato estatal brasileiro, a saber: o fascínio pela eficiência econômica setorial; o fascínio pela uniformidade e pelo controle do ambiente; o fascínio pela grande escala; e o fascínio pela modernidade. A visão tradicional do desenvolvimento, concebido, sobretudo, como um crescimento rápido e sustentado do produto nacional e padecendo de serialismo, etnocentrismo e dualismo preconceituoso, ignorava uma série de limites que o condicionam: limites $\mathrm{da}$ biosfera; limites do poder e recursos do Governo; limites de capacidade gerencial e limites à intrusão na esfera do cidadão.

$\mathrm{Na}$ mesma perspectiva de análise de fatores que condicionam as mudanças institucionais, Paulo Roberto Motta identifica uma série de fatores de controle político que tornam inócuas as estratégias e técnicas comumente utilizadas para a reforma do Estado latino-americano. Segundo seu raciocínio, o "Estado e suas estruturas burocráticas cumprem uma função determinada por sua construção histórica”, (МоттА, 1987, p. 31-32) caracterizada por "uma opção racional para a manutenção de valores e de sistemas tradicionais de poder. A burocracia pública 
veio sendo desenvolvida como um instrumento para atender aos interesses e às necessidades políticas de classes e grupos políticos preferenciais" (Ibid).

O Estado, como organização, constitui uma superestrutura com alicerces frágeis na sociedade. Os grupos e clãs políticos que se aglutinam no aparato estatal estão em busca de recursos para garantir sua sobrevivência, através de apoio de base e liderança. Os recursos obtidos são utilizados para satisfazer tanto a interesses políticos de poder como a interesses sociais particularísticos desses mesmos grupos, tais como os interesses privados de seus membros. Os grupos agem com a motivação de obter cooperação, ajuda e proteção mútua de seus membros, através de canais formais de administração, mas também de uma organização informal, ou seja, uma rede de apoio, de comunicação e de interação ligada por laços de lealdade política e religiosa, de parentesco, de vizinhança, de compadrio, etc. São grupos atuantes e que transformam o Estado num campo minado de lutas políticas, mantidas nos limites de atuação do Estado através de um equilíbrio dinâmico de forças, para não ferir a aparente estabilidade e legitimidade do sistema. Por esse motivo, as discórdias são bem toleradas e, de preferência, não-declaradas e confinadas à arena política predeterminada, que é o Estado. Esses grupos fazem parte de um contexto social, político e econômico que define o Estado e, portanto, não se pode ignorá-los no atual estágio de desenvolvimento da região, quando se pensa em estratégias de modernização do aparelho estatal (Ibid).
Entre os fatores que garantem a sobrevivência do sistema de clãs tradicionais na América Latina podem ser mencionados: domínio de estruturas formais de articulação e agregação de interesses (partidos, por exemplo); controle das estruturas burocráticas do governo; paternalismo e assistencialismo; delimitação dos conflitos políticos à arena do Estado; e restrição à livre iniciativa (Ibid, p. 32-34). A permanência desses fatores faz com que

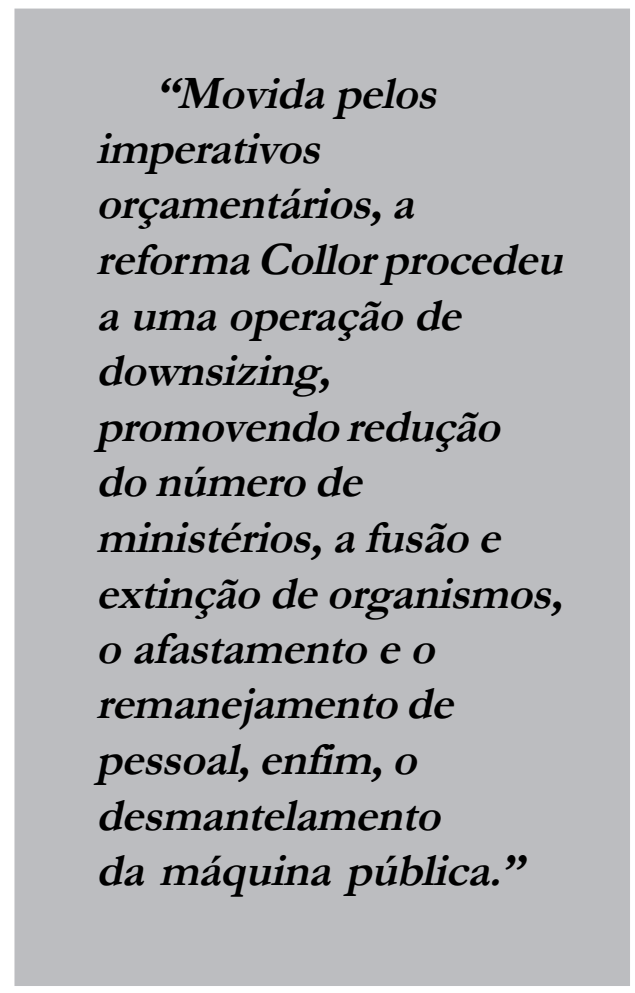

tanto a expansão das atividades do Estado quanto o aumento da sua eficiência, ao invés de promoverem maior eqüidade na participação (na gestão e no controle social) e no acesso (aos bens e serviços oferecidos pela administração pública), sirvam para fortalecer e colocar novos recursos nas mãos dos mesmos grupos preferenciais.

A reforma administrativa do Governo Collor foi uma das que mereceram menos 
referências bibliográficas e estudos aprofundados. As primeiras análises foram realizadas logo no início do governo, através de uma avaliação dos primeiros cem dias, procedida por um grupo de professores da Escola Brasileira de Administração Pública - EBAP (mais tarde, EBAPE), que resultou na publicação de um número especial da Revista de Administração Pública (RAP, no 1, 1990). Apoiados em diplomas legais e documentos oficiais, Lustosa da Costa e Cavalcante se detiveram sobre os aspectos formais da mudança, que consistiu, sobretudo, num vasto e profundo rearranjo estrutural. Movida pelos imperativos orçamentários, a reforma Collor procedeu a uma operação de downsiz̨ing, promovendo redução do número de ministérios, a fusão e extinção de organismos, o afastamento e o remanejamento de pessoal, enfim, o desmantelamento da máquina pública. Os autores tentam identificar a concepção de Estado que estava presente naquela reforma, apontar as contradições do modelo, estudar as contingências e analisar seus objetivos e resultados. Para tanto, agrupam as medidas em duas grandes categorias: a racionalização e a desestatização. $\mathrm{Na}$ primeira estratégia estariam contempladas as medidas orientadas para o aumento da eficiência e a redução de gastos, cabendo analisar os aspectos relacionados com as fusões e incorporações, o alcance de controle, a estrutura matricial, a tendência à uniformização, a supervisão ministerial, a coordenação e integração e a regionalização. A estratégia de desestatização tem o propósito de reduzir a interferência do Estado no domínio econômico, em particular, e na vida social em geral, e contempla a extinção de empresas e organismos, as privatizações, a descentralização e a desregulamentação.
Lustosa da Costa e Cavalcanti (1990) concluem que a reforma tinha um forte componente ideológico, no sentido do compromisso com a proposta neoliberal. Por outro lado, apoiava-se em um modelo burocrático mecanicista, valendo-se das suas formas tradicionais de arquitetura organizacional - o uso da hierarquia como mecanismo-chave de coordenação da interdependência e fortalecimento da administração-meio. Por último, chamavam a atenção para a estratégia de implantação, caracterizada por gestos de impacto e medidas espetaculares, denotando improviso e açodamento.

A reforma administrativa do Governo Collor também suscitou análises relacionadas com o novo padrão de agregação de interesses e influenciação estabelecidos com a criação das chamadas Câmaras Setoriais (DinIz, 1997). No contexto da Ciência Política, tratava-se de uma primeira geração de estudos sobre a reforma do Estado, centrada "no impacto diferencial da transição democrática sobre a condução das políticas de reforma no mercado" (Melo, 1999, p. 83-84).

No período de transição que se seguiu ao impeachment do presidente Collor e mesmo no início do governo Fernando Henrique, o tema da reforma do Estado foi objeto de discussão mais uma vez no Fórum Nacional, conclave realizado anualmente, sob a liderança do ex-ministro do Planejamento João Paulo dos Reis Velloso, por iniciativa do Instituto Nacional de Altos Estudos (INAE). Roberto Cavalcante de Albuquerque (1995), diretor técnico do INAE, apresentou em maio de 1995 um alentado estudo sobre reconstrução e reforma do Estado. Ele traça um esboço de arqueologia e história do Estado Nacional, desde suas raízes ibéricas (11391500), passando pelo patrimonialismo e 
a centralização (1500-1508) da Colônia, pelo Estado que se sobrepõe à sociedade (18081930) e pelo Estado como superinstituição (1930-1980), até o período de desagregação que é, ao mesmo tempo, o limiar para novos caminhos (1980-1995). Afora o recuo histórico até a constituição da monarquia portuguesa e a periodização adotada, sua narrativa não difere muito das outras. $\mathrm{O}$ toque original é a caracterização da crise, de tríplice natureza, que se instalou na década de 1980 - crise de legitimidade do Estado autoritário, crise financeira e crise existencial. Esta última se caracteriza por "afetar os alicerces institucionais e a identidade do próprio ente estatal: sua razão de ser e consciência de si mesmo; sua capacidade decisória e funcionalidade; sua percepção da sociedade; e a imagem que projeta perante ela" (p. 142). Manifesta-se pela inexistência de um "projeto de desenvolvimento que dê sentido, estabeleça limites e confira direção às ações públicas" (Ibid) pelo estiolamento da autoconsciência do Estado, pela incapacidade de manter a hierarquia e a disciplina internas, de processar informações, de fazer fluir a comunicação intergovernamental e de acionar a miríade de mecanismos de controle à sua disposição.

A capacidade decisória de governo esgarçou-se na transição democrática, que passou a demandar processos de decisões politicamente negociados, mais abertos e participativos, mas deparou-se com a resistente couraça ainda autocrática do Estado: diante do jogo contraditório de pressões e de interesses, quase sempre contemporização, impasse e recuo, ou imposição da autoridade; quase nunca negociação convergindo para o compromisso possível (Id).
Mergulhado nessa crise, sem que os principais atores percebessem as transformações que se processavam no mundo globalizado e na própria sociedade brasileira, o Estado era pressionado por duas forças contraditórias. De um lado, a agenda negativa - cujas palavras-chave eram desmonte, desburocratização, descentralização, desestatização - era ditada pelas imposições financeiras ou por "preconceitos, de confusa inspiração e escassa verificabilidade, que associavam, necessariamente, e de modo reativo e equivocado, desregulamentação a mais liberdade, desburocratização a menos governo, descentralização a mais democracia, desestatização a mais eficiência" (Ibid, p. 143). De outro, o poder constituinte reafirmava a presença do Estado como superinstituição, fazendo inscrever na nova Carta novas competências, inclusive na infraestrutura e nos serviços a ela associados, monopólios de petróleo, minerais e telecomunicações, privilégios a empresas nacionais em detrimento das estrangeiras e a elevação do mercado interno à categoria de patrimônio nacional.

Nilson Holanda (1993), que participou da estruturação da ENAP no âmbito do projeto reformista do Governo Sarney, também apresentou no Fórum Nacional uma análise da crise gerencial do Estado brasileiro. Ele acredita que, a partir do início do

ciclo dos choques antiinflacionários, com o Plano Cruzado (1986), (...) a reforma administrativa passa a ser concebida (...) equivocadamente como elemento auxiliar dos planos de estabilização, através da fusão e extinção de órgãos e empresas, com o objetivo de 'enxugar' a estrutura da Administração Federal (p. 170-171). 
As crescentes dificuldades econômicas e a emergência do debate constitucional fizeram com que o ânimo reformista fosse enfraquecido. Essa análise histórica o leva a levantar algumas hipóteses para explicar a crise gerencial do Governo Federal:

- O conflito permanente entre atividades-fim, em busca de descentralização e autonomia gerencial, e atividades-meio, requerendo centralização e controle, acabou sendo vencido pelas forças centralizadoras, sem compromissos com resultados.

- Os "interregnos democráticos" acentuam a vulnerabilidade da administração pública brasileira às interferências políticas, como se verificou em 1945 e em 1985.

- O principal vilão da crise é o regime jurídico único (RJU) do servidor público, que os nivelou por baixo "em termos de remuneração, disciplina e desempenho", atingindo duramente alguns centros de excelência.

- Apesar do RJU e sua propalada isonomia, foram criadas carreiras privilegiadas, sobretudo nas áreas jurídicas e de fiscalização, com salários muito acima da média, inclusive daqueles antigos centros de excelência.

- A perda do poder aquisitivo dos salários suscitou o desenvolvimento de uma estratégia de sobrevivência baseada em "corporativismo, arregimentação sindical e alienação em relação aos fins da administração pública” (Ibid, p.173-175).

Humberto Falcão Martins se debruçou duas vezes sobre a experiência brasileira de reforma da administração pública, sempre colocando em primeiro plano o contexto político. $\mathrm{Na}$ primeira oportunidade, discutiu "a modernização da administração pública brasileira no contexto do Estado" a partir do exame das relações entre política e administra- ção. Ele procura mostrar que há uma "relação disfuncional entre burocracia e democracia”. A história da modernização é o relato do processo de consolidação de "uma cultura, um modelo de mudança e uma imagem da boa administração pública instrumentais, restritos à modernização administrativa, dissociados do contexto político do Estado" (Martins, 1995, p. 82).

A escolha da modernização como categoria central da análise coloca alguns problemas. Quem diz modernização diz secularização e racionalização; quem diz racionalização, quase sempre, como é o caso, evoca os tipos de racionalidade da ação social propostos por Weber, pois "a modernização implica racionalização funcional e substantiva" (Ibid, p. 183). A distinção entre irracionalidade, racionalidade substantiva e racionalidade funcional (ou instrumental) nem sempre permite saber se a apreciação dos objetos se faz a partir de categorias de análise ou julgamentos de valor. Assim, a "irracionalidade do sistema político" responde por disfunções da administração pública. Por outro lado, as tentativas de aumento $\mathrm{da}$ racionalidade funcional inerente à burocracia, por natureza limitada, não favorecem o desenvolvimento de uma administração democrática. Trata-se de uma modernização incompleta porque

ora tentou-se consolidar uma burocracia, racionalizando-se funcionalmente a administração, à revelia da política e à custa da democracia; ora tentou-se descaracterizar seu caráter (sic) funcional, pretensamente até em nome da democracia, o que resultou no desenvolvimento de uma burocracia estatal com baixa racionalidade social (Ibid, p. 117). 
A política "irracional" é nociva à administração "funcionalmente" racional. Embora o autor prescreva toda uma estratégia de modernização, seu trabalho não deixa claro como seria o sistema político racional capaz de deixar prevalecer a racionalidade substantiva na administração pública e fazer prosperar um relação funcional entre democracia e burocracia.

Desde a primeira formulação do Plano Diretor da Reforma do Aparelho do Estado, Bresser Pereira também procurou examinar a experiência brasileira de reforma administrativa. Seu relato é linear e não difere muito das narrativas precedentes. O que caracteriza a sua análise histórica é a ênfase nas duas grandes reformas do século passado, simplificando a periodização e a perspectiva nitidamente evolucionista que adota. Valendo-se de noções weberianas e das prescrições da New Public Management, ele distingue historicamente três tipos de administração pública: a patrimonialista, a burocrática e a gerencial.

$\mathrm{Na}$ administração pública patrimonialista, o aparelho do Estado funciona como uma extensão do poder soberano, e os seus auxiliares e servidores possuem status de nobreza real. Os cargos são considerados prebendas. A res publica não é diferenciada da res principis. A corrupção e o nepotismo são inerentes a esse tipo de administração. Segundo Weber, com o desenvolvimento do capitalismo e da democracia de massas, eles tendem a se tornar residuais.

A administração pública burocrática se caracteriza pela profissionalização, a idéia de carreira, a hierarquia funcional, a impessoalidade, o formalismo, em síntese, o poder racional legal. Os controles administrativos, visando evitar a corrupção e o nepotismo, são sempre a priori. Parte-se de uma desconfiança essencial nos adminis- tradores públicos e nos cidadãos que a eles dirigem demandas. $\mathrm{O}$ controle rígido dos processos volta-se para a administração de pessoal, as compras e o processamento de demandas.

A administração pública gerencial é orientada predominantemente pelos valores da eficiência e da qualidade na prestação de serviços públicos e pelo desenvolvimento de uma cultura gerencial nas organizações. Não nega todos os princípios da adminis-

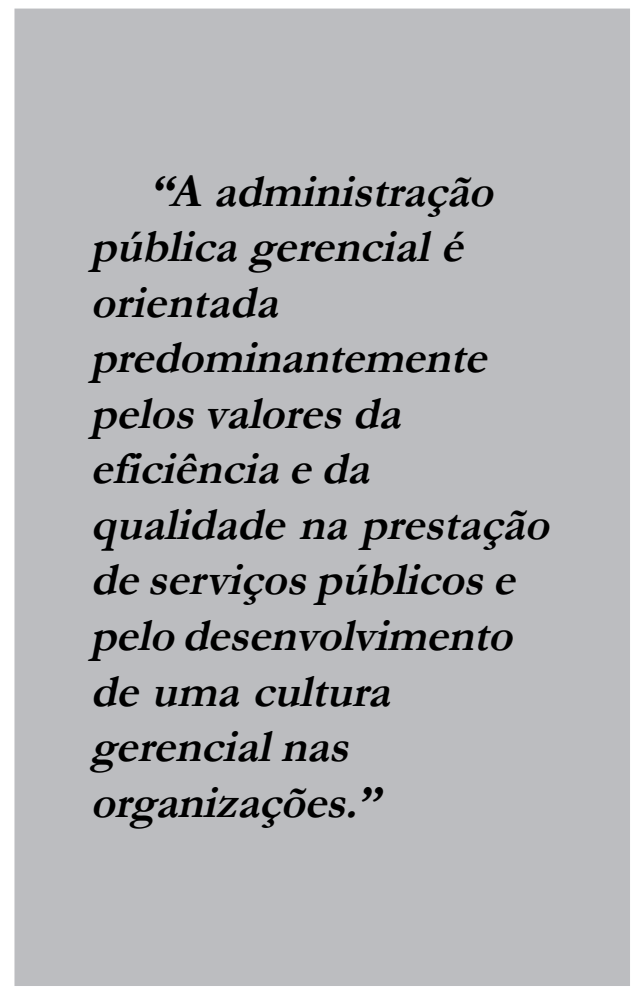

tração pública burocrática, pois tem uma clara noção do interesse público e conserva, embora flexibilizando-os, a admissão segundo critérios de mérito, a existência de um sistema estruturado de carreiras, a avaliação constante de desempenho e o treinamento sistemático. A principal diferença está na forma de controle, que deixa de se basear nos processos para se concentrar nos resultados. 
O caráter evolucionista e voluntarista dessa tipologia é evidente. A emergência do Estado nacional e do poder absoluto propiciou o desenvolvimento da administração patrimonialista. O desenvolvimento do capitalismo e da moderna democracia de massas ensejou o surgimento da administração burocrática. A ampliação dos direitos de cidadania, o fortalecimento da sociedade civil e a derrocada do keynesianismo impuseram o advento da administração gerencial, que corresponde ao fim da história da administração pública. Em português brasileiro, essa designação constitui um pleonasmo abominável, pois as palavras administração, gerência e gestão são sinônimas. Embora se pretenda nomear um modelo de gestão em que prevalecem valores e técnicas próprias ao mundo empresarial (management), falar em administração gerencial é o mesmo que se referir a uma administração administrativa.

Belmiro Valverde de Jobim Castor (2000) também faz a sua retrospectiva histórica e formula uma hipótese para o fato de as reformas administrativas não darem certo. Sua análise retoma a noção de formalismo para mostrar por que no Brasil há leis "que pegam” e leis que "não pegam", quer dizer, porque as leis são obedecidas ou não. Ele recorre às interpretações clássicas para mostrar que as leis pegam para uns e não pegam para outros, ou melhor, que sua observância depende da posição social do interessado e daqueles a quem compete fazer cumpri-las. Nesse contexto, a mudança institucional obedece à dialética da reforma e da contra-reforma. Forças antagônicas contrapõem de um lado

uma burocracia formalista, ritualista, centralizadora, ineficaz e infensa à modernização do aparelho do Estado, aliada dos interesses econômicos mais retrógrados e conservadores, luta para manter as coisas como estão; e, de outro, as correntes modernizantes da burocracia apoiadas por seus próprios aliados políticos e empresariais lutam para mudar e inovar (p. 150).

O autor prossegue com uma descrição pertinente dessa dinâmica, parecendo tomála como a própria explicação do fenômeno. É verdade que movimentos contraditórios têm marcado a história da modernização do Estado brasileiro. Tendências descentralizadoras logo são anuladas por movimentos de centralização. Iniciativas de flexibilização são inibidas por controles uniformes. Autonomias duramente conquistadas são, em pouco tempo, submetidas aos padrões comuns de hierarquia e disciplina. O que está na raiz dessas reviravoltas é a impossibilidade de adotar modelos mais flexíveis e descentralizados em toda a administração pública, que se guia por leis universalistas. Flexibilidade e autonomia custam caro e não podem ser dadas a todos. Sempre que aumenta o número dos que as conquistam, pressionando as contas públicas, surgem normas uniformes para submetê-las aos controles centralizados. Não se trata do choque de forças voluntaristas de caráter progressista ou reacionário, mas simplesmente da própria lógica de funcionamento dos sistemas burocráticos.

Além de relacionar e analisar as razões para as baixas performances das reformas administrativas, Flávio Rezende (2004) também apresenta sua própria teoria explicativa para a falha seqüencial. Sua visão particular de reformas administrativas as concebe como políticas que

visam em última instância à melhoria (ou elevação) da performance de um dado sistema burocrático. (...) são tentativas de reorganizar o controle 
burocrático através do ajuste fiscal (ou de um ponto de vista mais abrangente, a eficiência e a racionalidade dos custos) e da mudança institucional (em um sentido mais amplo, a criação de instituições formais e informais no interior do sistema burocrático dotadas de maior flexibilidade, responsabilidade e capacidade de garantir 'maior retorno' ante a demanda) (p. 14-15).

Sua hipótese é que esses objetivos são conflitantes, pois o ajuste fiscal impõe maior controle sobre o sistema burocrático, enquanto a mudança institucional demanda maior autonomia para as partes desse mesmo sistema. Os atores comprometidos com um desses objetivos tendem a não cooperar para a consecução do outro. No caso da reforma do primeiro mandato do presidente Fernando Henrique, a extinção do Ministério da Administração e Reforma do Estado (MARE) decorreu da incapacidade de promover mudanças institucionais num governo comprometido prioritariamente com o ajuste fiscal. A reforma enfrentava resistências tanto da parte dos órgãos de controle, receosos da possibilidade de ampliação da autonomia dos executores de atividades-fim, quanto dos órgãos que deveriam sofrer transformações, temerosos da perda da tutela governamental e da correspondente garantia de dotações orçamentárias.

Essa tese encontra pelo menos uma evidência em contrário no Brasil - a reforma administrativa de 1967, empreendida na seqüência de um rigoroso programa de ajuste fiscal. De fato, o Decretolei $\mathrm{n}^{\circ} 200$ criou, ao mesmo tempo, os procedimentos uniformes de gestão e controle e os mecanismos de flexibilização administrativa. Havia, dentro da mesma reforma, no mesmo instrumento legal, diretrizes para o controle centralizado e para a autonomia dos organismos públicos. De um lado, criavam-se os planos nacionais, o orçamento por programas, o sistema federal de controle e as normas de licitação e contratos; de outro, reconheceram-se as especificidades da administração indireta e a necessidade de autonomia das empresas e fundações públicas.

A segunda apreciação de Humberto Martins sobre as reformas administrativas brasileiras toma como referência três casos de políticas de gestão pública, dos quais participou diretamente, conduzidos nos dois mandatos de Fernando Henrique Cardoso, mas os apresenta no contexto da formulação de uma teoria geral, ainda que de médio alcance (MERTON, 1970), da fragmentação de políticas públicas. Ele propõe uma explicação adicional para os escassos resultados dos processos de reforma. Sua hipótese é que

às políticas de gestão pública no período 1995-2002 subjaz o fenômeno da fragmentação, e este constitui um explicação válida para a descontinuidade e a baixa implementação. Argumenta-se, nesse sentido, que as dinâmicas dos processos constitutivos das políticas de gestão evidenciam não apenas diversidade, mas baixa integração, conflito e anulação recíproca. A análise das dinâmicas constitutivas de episódios nesse período poderá levar à corroboração dessa hipótese, relevando não apenas diferenças de visão entre seus empreendedores, de percepção de problemas e soluções, de valores incrustados nas culturas de suas instâncias institucionais mas, sobretudo, a inexistência ou o malogro de elementos de integração e convergência. 
Em síntese, a Teoria da Fragmentação de Políticas propõe que: a fragmentação representa a perda de coerência, consistência e coordenação nas políticas de um mesmo subsistema e entre diversos subsistemas; e é um resultado indesejado dos processos de formulação e implementação de políticas, associado a elementos estruturais tais como liderança executiva, estratégia, ajustamento mútuo, estrutura formal de coordenação, processos e valores (MARTins, 2003, p. 20-21).

Não cabe discutir aqui todos os aspectos da ambiciosa e sofisticada formulação teórica. Interessa chamar atenção para o fato de que essa teoria, como explicação adicional da descontinuidade e baixa implementação da(s) reforma(s), acrescenta pouco. Em primeiro lugar, certo nível de fragmentação é inerente a qualquer política pública complexa que contemple objetivos amplos e diversificados, envolva grande número de atores interessados e esteja estreitamente relacionada a outras políticas. Em segundo lugar, o próprio autor, para efeitos de análise, fragmenta a política de reforma em três fases, quando se trata de um único processo que foi perdendo impulso desde o fim do primeiro mandato do presidente Fernando Henrique. Em terceiro lugar, o conjunto de elementos estruturais indicado faz parte das outras explicações a que esse vem acrescentar-se. Por último, o mais importante - a explicação proposta pela teoria é utilizada em um modo post hoc. Se as políticas são descontínuas e apresentam escassos resultados, devem ser encontrados elementos de fragmentação; se as políticas são contínuas, progressivas e exitosas, podem ser encontrados elementos de integração.

\section{Considerações finais}

A recuperação das principais análises dos processos de reforma administrativa no Brasil produz uma crônica tediosa, pois as narrativas são repetitivas. Partem sempre dos mesmos pressupostos e fazem as mesmas "descobertas". São quase unânimes em apontar as raízes históricas das disfunções da administração pública, identificando no patrimonialismo e no clientelismo as principais distorções, mas não aprofundam o estudo das conseqüências desses fenômenos sobre a organização governamental, as práticas administrativas e as próprias tentativas de reforma. Também há grande convergência na percepção do caráter autoritário das reformas de 1937 e 1967, embora quase todos reconheçam nelas avanços importantes para a modernização da máquina pública. Com relação à reforma de 1967 , há mesmo certa nostalgia da linearidade, da uniformidade, da simetria e das ambições do planejamento e da gestão tecnocráticas.

Alguns pontos merecem ser destacados para compor um quadro mais completo e elucidativo, entre os quais cumpre indicar a análise estratégica de Kleber Nascimento, a perspectiva sociopolítica de Paulo Motta, os insights de Castor e França e a análise da crise existencial do Estado subscrita por Roberto Cavalcanti de Albuquerque. Devese fazer menção também a uma brevíssima referência de Sheila Ribeiro (2002) às transformações nos instrumentos e nas instituições encarregadas de implementar as políticas sociais. Essas indicações permitem lançar as bases de uma nova história da modernização administrativa no Brasil.

(Artigo recebido em julho de 2008. Versão final em setembro de 2008). 


\section{Notas}

* Este artigo nasceu de um dos capítulos da tese de doutoramento em Gestão intitulada "Reforma Gerencial do Estado no Brasil - condicionantes, estratégias e resultados", defendida junto ao Instituto Superior de Ciências do Trabalho e da Empresa - ISCTE, em Lisboa, em junho de 2007.

${ }^{1}$ Tradução do autor: "Governments have promised as much as before but they to often failed to improve their performances simply because many reforms have proved disappointing. Reforms have failed to make any significant impact; they have gone wrong; they have been overtaken by events. The reformers have been too optimistic and often unrealistic; they have fallen into the traps of implementation. Reforms need strong political backing, mass support, and competent inside facilitation. Reformers need to take the ir times and accept what they can achieve even if the resultants fall short of their intensions".

${ }^{2}$ Luís Simões Lopes, de origem sulina, era um próximo colaborador do presidente Vargas. Participou da reforma administrativa desde o seu começo, tendo sido o primeiro presidente do DASP. Foi o criador da Fundação Getúlio Vargas, instituição que presidiu por 48 anos.

\section{Referências bibliográficas}

Beltrão, Helio (1984). Centralização e liberdade, Rio de Janeiro, Record.

Bento, Leonardo Valles (2003). Governança e governabilidade na reforma do Estado, Barueri, Manole.

Bertero, Carlos Osmar (1986). Perspectivas históricas e eventos recentes, Brasília, FUNCEP. Bresser Pereira, Luís Carlos (1998). Reforma do Estado para a cidadania: a reforma gerencial brasileira na perspectiva internacional, Brasília, Ed. 34.

. Do Estado patrimonial ao gerencial, in Pinheiro, Paulo Sérgio; Wilheim,

Jorge e SACHs, Ignacy (orgs.). Brasil: um século de transformações. São Paulo, Companhia das Letras, 2001.

CAIDEN, Gerald E.. Administrative reform: proceed with caution, in International Journal of public Administration, 22(6), 815-832, 1999.

CAstor, Belmiro Valverde Jobim. O Brasil não é para amadores. Estado, Governo e Burocracia na terra do jeitinho, Curitiba, EBEL, 2000.

Castor, Belmiro Valverde \& FrançA, Célio. Administração pública no Brasil: exaustão e revigoramento do modelo, in Revista de Administração Pública, 20 (3): 3-26, 1986.

Cavalcanti de Albuquerque, Roberto. Reconstrução e Reforma do Estado, in Velloso, João Paulo dos Reis \& Cavalcanti De Albuquerque, Roberto (orgs.). Governabilidade e Reformas. Rio de Janeiro, José Olympio, 1995.

Cavalcanti, Bianor Scelza \& OTERo, Roberto Bevilacqua. Novos padrões gerenciais no setor público: medidas do governo americano. Brasília: ENAP, 1997.

Fleury, Sonia. Democracia, descentralização e desenvolvimento, in Democracia descentralização e desenvolvimento: Brasil e Espanha. Rio de Janeiro, Fundação Getúlio Vargas, 2006. 
Guerreiro Ramos, Alberto. Administração e contexto brasileiro. Rio de Janeiro, Fundação Getúlio Vargas, 1983.

Holanda, Nilson. A crise gerencial do Estado brasileiro, in VELLOSO, João Paulo dos Reis (org.). Brasil: a superação da crise. São Paulo, Nobel, 1993.

LiMA JúnIOR, Olavo Brasil .As reformas administrativas no Brasil: modelos, sucessos e fracasso, in Revista do Serviço Público, 49 (2), 1998.

Lustosa da Costa, Frederico. Estado, reforma do Estado e democracia no Brasil da Nova República, in Revista de Administração Pública, 32(4), 71-82, 1998.

, \& Cavalcanti, Bianor Scelza, Mudança organizacional no setor público, in Revista de Administração Pública, 25(1), 82-106, 1991.

, \& PECI, Alketa, Desestatização como estratégia de Reforma do Estado: análise preliminar da privatização no Brasil da Nova República, in Revista de Administração Pública, 33 (3), 191-207, 1999.

Machiavelli, Nicoló di Bernardo dei (2006), O príncipe, Porto Alegre, L\&PM.

Marcelino, Gileno Fernandes. Evolução do Estado e reforma administrativa. Brasília, Sedap, 1987.

. Governo, imagem e sociedade. Brasília, FUNCEP, 1988.

. Em busca do Estado moderno: as reformas administrativas planejadas

no Brasil, in Revista Recursos Humanos, ano I n 2, Brasília, Instituto de Recursos Humanos (IDR), 39-44, 1993.

. Em busca da flexibilidade do Estado: o desafio das Reformas Planejadas no Brasil, in Revista de Administração Pública, 37(3), 641-659, 2003.

Mare. Plano Diretor da Reforma do Aparelho do Estado. Brasília, Presidência da República, Imprensa Oficial, 1995.

Martins, Humberto Falcão. A modernização da administração pública brasileira no contexto do Estado. Dissertação de mestrado apresentada à Escola Brasileira de Administração Pública. Fundação Getulio Vargas, Rio de Janeiro, 1995.

- Uma teoria da fragmentação de políticas públicas: desenvolvimento e aplicação na análise de três casos de políticas de gestão pública. Tese apresentada à Escola Brasileira de Administração Pública e de Empresas. Fundação Getulio Vargas, Rio de Janeiro, 2003.

Melo, Marcus André (org.). Reforma do Estado e mudança institucional no país. Recife, Massangana, 1999.

. Estado, governo e políticas públicas, in Sérgio Miceli, O que ler na ciência social brasileira. São Paulo, Sumaré, 1999.

Reformas constitucionais no Brasil: instituições políticas e processos decisórios.

Rio de Janeiro, Revan, 2002.

NAscimento, Kleber. Reflexões sobre estratégia de reforma administrativa: a experiência federal brasileira, in Revista de Administração Pública, 1967.

PACHECO, Regina Sílvia. Regulação no Brasil: desenho das agências e formas de controle in Revista de Administração Pública, 40(4), 523-543, 2006. 
Petrucci, Vera \& Schwarz, Letícia (orgs.). Administração pública gerencial: a reforma de 1995. Brasilia, UNB/ENAP, 1999.

Pinho, José Antônio Gomes de, Reforma do Aparelho do Estado: Limites do Gerencialismo frente ao Patrimonialismo, in Organização \& Sociedade, 5(12), 59-79, 1998. Rezende, Flávio da Cunha. Por que falham as reformas administrativas. Rio de Janeiro, Fundação Getúlio Vargas, 2004.

Ribeiro, Sheila Maria Reis. Reforma do Aparelho de Estado no Brasil: uma comparação entre as propostas dos anos 60 e 90, in VII Congreso del CLAD, Lisboa, 1-21, 2002.

TOrRes, Marcelo Douglas de Figueiredo. Estado, democracia e administração pública no Brasil. Rio de Janeiro, Fundação Getúlio Vargas, 2004.

Velloso, João Paulo Reis e Cavalcanti Albuquerque, Roberto (orgs.). Governabilidade \& Reformas. Rio de Janeiro, José Olympio, 1995.

Wahrlich, Beatriz Marques de Souza. Reforma administrativa federal brasileira: passado e presente, in Revista de Administração Pública, (8), 27-75, 1974.

. O governo provisório de 1930 e a Reforma Administrativa, in Revista de Administração Pública, 9(4), 5-68, 1975.

- Institucionalização da reforma administrativa: atuação do Conselho Federal de Serviço Público Civil e da Comissão Permanente de padronização (1936 a 1938), in Revista de Administração Pública, 10(4), 21-54, 1976.

. Desburocratização e desestatização: novas considerações sobre as prioridades brasileiras de Reforma Administrativa na década de 80, in Revista de Administração Pública, 18(4), 72-87, 1984. 


\section{Resumo - Resumen - Abstract}

\section{História das reformas administrativas no Brasil: narrativas, teorizações e representações} Frederico Lustosa da Costa

O trabalho se propõe a oferecer uma modesta contribuição ao estudo da história das reformas administrativas realizadas no Brasil a partir da primeira metade do século XX. Mais do que apresentar uma cronologia de fatos e um repertório de projetos, recupera as narrativas e análises dos estudiosos do tema para identificar as diferentes explicações para os sucessos e insucessos do passado e estabelecer um sistema de categorias que seja útil à compreensão da dinâmica histórica. Relatos, narrativas, teorizações, interpretações e ideologias se confundem. Em qualquer um dos casos, constituem representações do mundo administrativo brasileiro, quer dizer, apresentam-se como formas simbólicas de um Estado em transformação.

Palavras-chave: dinâmica histórica, reformas administrativas, Estado.

\section{Historia de las reformas administrativas en Brasil: narrativas, teorizaciones y representaciones} Frederico Lustosa da Costa

El trabajo intenta ofrecer una modesta contribución para el estudio de la historia de las reformas administrativas realizadas en Brasil, empezando en la primera mitad del siglo XX. Además de presentar la cronología de los hechos y la colección de proyectos, retoma las narrativas y análisis de los expertos para identificar las diferentes explicaciones para los éxitos y fallos del pasado y para establecer un sistema de categorías útil a fin de comprender la dinámica histórica. Relatos, narraciones, teorizaciones, interpretaciones e ideologías se confunden. En todo caso, constituyen representaciones del mundo administrativo, es decir, se presentan como formas simbólicas del Estado en cambio.

Palabras clave: dinámica histórica, reformas administrativas, Estado

\section{History of the Administrative Reforms in Brazil: Narratives, Theorizations and Representations} Frederico Lustosa da Costa

The article intends to offer a modest contribution to the study of the history of administrative reforms accomplished in Brazil starting from the first half of the 20th century. More than to present a chronology of facts and a repertoire of projects, it recovers the narratives and the specialists' analyses of the theme to identify the different explanations for the successes and failures of the past and to establish a system of categories, useful to the understanding of the historical dynamics. Reports, narratives, theorizations, interpretations and ideologies are mixed. In any one of the cases, they constitute representations of the Brazilian administrative world, that is, they come as symbolic forms of a State in constant transformation.

Key words: historic dynamics, administrative reforms, State.

Frederico Lustosa da Costa

Graduado em Economia; Mestre em Administração Pública e Ciência Política e doutor em Gestão. Atualmente é professor titular da Escola Brasileira de Administração Pública e de Empresas (EBAPE) da Fundação Getúlio Vargas.

Contato: frederico.lustosa@fgv.br 